\title{
Differential Expression of Placental Glucocorticoid Receptors and Growth Arrest-Specific Transcript 5 in Term and Preterm Pregnancies: Evidence for Involvement of Maternal Stress
}

\author{
D. Mparmpakas, ${ }^{1}$ E. Zachariades, ${ }^{1}$ G. Sotiriadis, ${ }^{1}$ A. Goumenou, ${ }^{1,2}$ A. J. Harvey, ${ }^{3}$ \\ Y. Gidron, ${ }^{1,4}$ and E. Karteris ${ }^{1}$ \\ ${ }^{1}$ Biosciences, Centre for Cell and Chromosome Biology, Brunel University, Uxbridge, UB8 3PH, UK \\ ${ }^{2}$ Department of Obstetrics and Gynecology, University Hospital, University of Crete Medical School, Heraklion, 71003 Crete, Greece \\ ${ }^{3}$ Biosciences, Brunel Institute for Cancer Genetics and Pharmacogenomics, Brunel University, Uxbridge, UB8 3PH, UK \\ ${ }^{4}$ Free University of Brussels (VUB), 1090 Jette, Belgium
}

Correspondence should be addressed to E. Karteris; emmanouil.karteris@brunel.ac.uk

Received 20 September 2013; Revised 18 January 2014; Accepted 12 March 2014; Published 11 May 2014

Academic Editor: Curt W. Burger

Copyright (C) 2014 D. Mparmpakas et al. This is an open access article distributed under the Creative Commons Attribution License, which permits unrestricted use, distribution, and reproduction in any medium, provided the original work is properly cited.

\begin{abstract}
Pregnancy-specific stress predicts birth outcomes. We hypothesized that there is a maternal stress-GR interaction that can influence fetal birth weight. This study examined the relationship between mothers' stress and attitude towards their pregnancies, placental glucocorticoid receptors (GRs) and growth arrest-specific transcript 5 (GAS5) expression, and the status of GR polymorphism, with their infants' birth weights. GAS5 and GR $\alpha$ were the predominant transcripts in both term and preterm placentas, with GAS5 being primarily localized in the syncytiotrophoblasts. In an attempt to mimic moderate and high stress environment in vitro, BeWo and JEG-3 cytotrophoblast cell lines were treated with $10 \mathrm{nM}-1000 \mathrm{nM}$ cortisol. Only expression of GAS5 was significantly upregulated by cortisol in all treatments compared with basal levels, but none of the GRs changed expression significantly. In an attempt to assess a stress versus gene interaction, we studied four GR polymorphisms. In the homozygous group for Tth111I polymorphism, mothers with negative attitudes towards the pregnancy gave birth to infants with significantly lower birth weights compared to women with positive/neutral attitudes. None of the GR splice variants were associated with maternal stress. However, placental GAS5 levels were inversely correlated with maternal stress. This study points towards a potential gene-environment interaction that could be of predictive value for fetal weight.
\end{abstract}

\section{Introduction}

Pregnancy is associated with major physiological and future psychosocial changes and adaptation to these changes is crucial for normal fetal development and for healthy infantmother relationships. Maternal pregnancy-specific stress may be a more powerful contributor to birth outcomes than general stress [1]. Biologically, the stress hormone cortisol acts by activating glucocorticoid receptors (GRs). To date, four splice variants of the GR gene have been reported, formed by alternative splicing, termed GR $\alpha, \mathrm{GR} \beta, \mathrm{GR} \gamma$, and GR-P [2]. Numerous studies have also reported the expression of different GR splice variants in different cell and tissue types [3-6]. Growth arrest-specific transcript 5 (GAS5) encodes a single strand noncoding RNA (ncRNA) and, as its name suggests, can accumulate in growth-arrested cells [7]. In a recent study by Kino and colleagues it was demonstrated that GAS5 ncRNA may be a repressor for the GR by acting as a decoy "glucocorticoid response element (GRE)," thus, competing with DNA GREs for binding to the GR. As a result, GRs cannot bind to their DNA GRE and subsequently their function is compromised [8].

Changes in the epigenetic regulation of the fetal GR promoter have been associated with exposure to prenatal 
maternal stress [9] reflecting a possible effect of maternal stress on the expression and function of the GR in the fetus. A GR BclI polymorphism has been associated with increased glucocorticoid sensitivity and was overrepresented in pregnant women with pathological, fetomaternal immune adaptation. Indeed, a number of polymorphisms have been described in the gene coding for the GR although it is still unclear whether the variability in the glucocorticoid responses observed is due to the polymorphisms or to other factors [10]. This sensitivity could be one mechanism linking maternal stress to fetal development. Only few of these polymorphisms are functionally relevant and these are the Tth111I, the ER22/23EK, the N363S, the-already mentioned-BclI, and the GR-9 $\beta$. Studies have shown that at least three polymorphisms are associated with altered glucocorticoid sensitivity and also with changes in body composition and metabolic parameters $[10,11]$, which could affect fetal development as well.

This study examined the relationship between mothers' stress levels and attitude towards their pregnancies, placental GR and GAS5 expression, and the status of GR polymorphism, with their infants' birth weights. We also examined the maternal attitude versus gene interaction in relation to fetal birth weight. Moreover, we tested the effect of cortisol on GR splicing and GAS5 expression of BeWo and JEG-3 placental cells, in an attempt to resemble a low, moderate, and high stress milieu in vitro.

\section{Methodology}

2.1. Subjects. The study population consisted of pregnant women attending the Department of Obstetrics and Gynaecology, University Hospital, University of Crete. The participants were in the third trimester of their pregnancy. All participants gave informed consent to participate in the study and ethical approval was granted by the local ethics committee of the hospital. Questionnaires regarding maternal stress/maternal attitudes as well as anthropometric data were collected as previously described $[12,13]$. Briefly, maternal stress/maternal attitudes towards their pregnancy were assessed in the 3rd trimester, using a questionnaire approach. A research nurse or a gynecologist conducted a face-toface interview with each woman lasting approximately 2030 minutes. Maternal attitudes were related to self-reported stress status ranging from low and medium (low stress response) to high and very high (high stress response). The exact cause of maternal stress was not identified. Maternal attitudes were divided into two groups: negative attitudes (48\%) and positive $(35.7 \%) /$ neutral attitudes (16.3\%). Immediately after delivery the weight of the newborn was recorded.

2.2. Placental Tissue. Placental tissues were obtained from women delivering at term ( $>37$ weeks of gestation) and preterm (<37 weeks of gestation) (total $n=23$ ). Of the 13 term placentas 12 were in labor (mode of delivery: 10 caesarean sections [CS], 2 vaginal deliveries) and 1 nonlabor/CS tissue. None of the term or preterm women were administered any antidepressants or synthetic glucocorticoids during pregnancy. Of the 10 term placentas 4 were nonlabor and all $\mathrm{CS}$, and 6 were from laboring tissues (mode of delivery: 3 CS, 3 vaginal deliveries). The average age was $29.6 \pm 4$ years, the mean pregnancy days were $240 \pm 42$, and mean fetal weight was $2805 \pm 95$ gr. After delivery, the maternal and fetal surfaces of the placenta were dissected, and fetal membranes were peeled away from the placenta. Placental samples were washed in PBS and immediately stored in RNAlater (Applied Biosystems, $\mathrm{UK}$ ) at $-80^{\circ} \mathrm{C}$. Ethical approval was granted from the local ethics authority.

2.3. Cell Culture. BeWo and JEG-3 cell lines were maintained at standard culture conditions of $5 \% \mathrm{CO}_{2}$ in air at $37^{\circ} \mathrm{C}$. BeWo cells were cultured in Ham F12 (Sigma-Aldrich, UK) containing $10 \%$ heat-inactivated fetal bovine serum (FBS) and $0.5 \%$ penicillin streptomycin, whereas JEG-3 cells were maintained in MEME (Sigma-Aldrich, UK) containing $10 \%$ heat-inactivated FBS and $0.5 \%$ penicillin streptomycin, $0.5 \%$ L-glutamine, $0.5 \%$ sodium pyruvate, and 0.5\% MEM nonessential amino acids. Prior to cortisol treatment, both cell lines were maintained for 3 hours in phenol red-free media containing charcoal stripped FBS.

2.4. RNA Isolation, cDNA Synthesis, and PCR. Total ribonucleic acid was isolated using an RNA extraction kit (SigmaAldrich, UK), according to manufacturer's instructions. RNA concentration was determined by spectrophotometric analysis (NanoDrop; Thermo Scientific, UK) and agarose gel electrophoresis. RNA (200 ng from placental tissue and $500 \mathrm{ng}$ from cell lysates) was reverse-transcribed into cDNA using $5 \mathrm{IU} / \mu \mathrm{L}$ RNase $\mathrm{H}$ reverse transcriptase (Invitrogen, Paisley, $\mathrm{UK})$.

2.5. Quantitative RT-PCR. Relative expression of the genes of interest was assessed by quantitative PCR (Q-PCR) on an ABI Prism 7900HT Sequence detection system (Applied Biosystems) using SYBR Green-PCR reaction mixture (SigmaAldrich, UK) and specific primers (Table 1) as previously described [14]. For the quantitative PCR, the following equations were used: $\Delta \mathrm{Ct}=\mathrm{Ct}_{\text {(gene of interest) }}-\mathrm{Ct}_{\text {(house keeping gene) }}$, $\Delta \Delta \mathrm{Ct}=\Delta \mathrm{Ct}_{(\text {sample })}-\Delta \mathrm{Ct}_{\text {(calibrator) }}$, and Relative Quantity $(\mathrm{RQ})=2^{-\Delta \Delta \mathrm{Ct}}$ as previously described [12].

2.6. Immunofluorescent Analysis. Following a series of deparaffinisation and dehydration, placental tissue sections were incubated with $10 \%$ bovine serum albumin (BSA) for $1 \mathrm{hr}$. This was followed by incubation for $1 \mathrm{hr}$ with antibodies against GR $\alpha$ at a 1:200 dilution in 1\% BSA/PBS. Cells were then washed with PBS prior to an incubation with a TRITCconjugated secondary antibody (Santa Cruz Biotechnology, USA) for $1 \mathrm{hr}$. Slides were washed with PBS and mounted in Vectashield Mounting Medium (Vector Labs) containing the dye 4,6-diamido-2-phenylindole (DAPI) to counterstain nuclei. Images were captured using a Plan Apo Neofluor 63X NA 1.25 oil objective (Zeiss) on a Zeiss Axiovert 200M microscope and viewed using the AxioVision software. 
TABLE 1: Sequences of primers used for quantitative RT-PCR.

\begin{tabular}{|c|c|c|c|}
\hline $\mathrm{GR} \alpha$ & $\begin{array}{l}\text { Sense } \\
\text { Antisense }\end{array}$ & $\begin{array}{l}5^{\prime} \text {-CTATGCATGAAGTGGTTGAAAA-3' } \\
5^{\prime} \text {-TTTCAGCTAACATCTCGGG-3 }{ }^{\prime}\end{array}$ & $96 \mathrm{bp}$ \\
\hline \multirow[b]{2}{*}{ GR $\beta$} & Sense & $5^{\prime}$-GAAGGAAACTCCAGCCAGAA-3' & \multirow[b]{2}{*}{$81 \mathrm{bp}$} \\
\hline & Antisense & 5'-CCACATAACATTTTCATGCATAGA-3' & \\
\hline $\mathrm{GR} \gamma$ & $\begin{array}{c}\text { Sense } \\
\text { Antisense }\end{array}$ & $\begin{array}{l}5^{\prime} \text {-TTCAAAAGAGCAGTGGAAGGTA-3' } \\
5^{\prime} \text {-GGTAGGGGTGAGTTGTGGTAACG-3' }\end{array}$ & $264 \mathrm{bp}$ \\
\hline GR-P & $\begin{array}{c}\text { Sense } \\
\text { Antisense }\end{array}$ & $\begin{array}{l}5^{\prime} \text {-GCTGTGTTTTGCTCCTGATCTGA-3' } \\
5^{\prime} \text {-TGACATAAGGTGAAAAGGTGTTCTACC-3' }\end{array}$ & $194 \mathrm{bp}$ \\
\hline GAS5 & $\begin{array}{c}\text { Sense } \\
\text { Antisense }\end{array}$ & $\begin{array}{l}5^{\prime} \text {-CAGTGTGGCTCTGGATAGCA-3' } \\
5^{\prime} \text {-TTAAGCTGGTCCAGGCAAGT-3' }\end{array}$ & $168 \mathrm{bp}$ \\
\hline$\beta$-Actin & $\begin{array}{c}\text { Sense } \\
\text { Antisense }\end{array}$ & $\begin{array}{l}\text { 5'-AAGAGAGGCATCCTCACCCT-3' } \\
5^{\prime} \text {-TACATGGCTGGGGTGTTGAA-3' }\end{array}$ & $216 \mathrm{bp}$ \\
\hline
\end{tabular}

2.7. Western Immunoblotting. Proteins from placental lysates and BeWo cells treated with $10-1000 \mathrm{nM}$ cortisol were separated on an SDS-12\% polyacrylamide gel and transferred to a nitrocellulose membrane. The membrane was blocked in TBS containing $5 \%$ dried milk powder $(\mathrm{w} / \mathrm{v})$ and $0.1 \%$ Tween20 , overnight at $4^{\circ} \mathrm{C}$. After three washes with TBS-0.1\% Tween-20, the nitrocellulose membranes were incubated with primary antibodies against GR $\alpha / \beta$ (Abcam, ab3580, UK) and GAPDH (Sigma-Aldrich, UK). The primary antisera were used at a $1: 1000$ dilution for GR $\alpha / \beta$ and $1: 2000$ for GAPDH, overnight at $4^{\circ} \mathrm{C}$. The membranes were washed thoroughly for $30 \mathrm{~min}$ with TBS- $0.1 \%$ Tween, before incubation with the secondary HRP-conjugated immunoglobulin $(1: 2000)$ for $1 \mathrm{hr}$ at room temperature and further washing for $30 \mathrm{~min}$ with TBS-0.1\% Tween-20. The immunoreactive bands were analyzed using Image J 1.34s image-analysis software (National Institute of Health, USA).

2.8. RNA Fluorescent In Situ Hybridization (FISH). The slides of the paraffin embedded placental tissue samples were placed in a coplin jar and deparaffinised for 30 minutes at $37^{\circ} \mathrm{C}$ using Histo-Clear (Fisher Scientific, UK). Thereafter, the tissue sections were rehydrated by placing the slides in ethanol solution of different concentrations $(100 \%, 90 \%, 80 \%, 70 \%$, $50 \%$, and $30 \%$ ) for 3 minutes. A brief wash in $1 \mathrm{x}$ PBS solution was performed after this. Pepsin $(0.01 \%$ in $0.01 \mathrm{M} \mathrm{HCl})$ was used to treat the tissue for 5 minutes at $37^{\circ} \mathrm{C}$, and a brief rinse in DEPC treated $\mathrm{H}_{2} \mathrm{O}$ followed. Then, the tissue samples were dehydrated by placing them in ethanol solutions $(70 \%, 90 \%$, and 100\%) for 5 minutes. A specific Alexa 488-conjugated GAS5 hybridization probe (GTGCTATCCAGAGCCACACTGCATCTGCACCCAGCACCATACCTCACAG) was utilised as previously described [8] and followed by an overnight incubation at $37^{\circ} \mathrm{C}$ in a humidified chamber. After this incubation, three 10 -minute washes were followed in $2 \mathrm{xSSC}$ at $37^{\circ} \mathrm{C}$. The slides were then briefly rinsed in DEPC treated $\mathrm{H}_{2} \mathrm{O}$ and mounted in Vectashield Mounting Medium containing DAPI prior to examining the emitted fluorescent signal under a Zeiss Axiovert 200M microscope viewed using the AxioVision software.
2.9. GR Polymorphisms. For the BclI, N363S, Tth111I, and ER22/23EK GR polymorphisms DNA was extracted using the Phusion Blood Direct PCR Kit (New England Biolabs, UK), according to the manufacturer's instructions. For the BclI, the following primers were used: $5^{\prime}$-AAGCTTAACAATGGCCAT- $3^{\prime}$ and $5^{\prime}$-TGCTGCCTTATTTGTAAATTCGT$3^{\prime}$. The PCR conditions used were 40 cycles of $98^{\circ} \mathrm{C}$ for $5 \mathrm{sec}$, annealing at $50^{\circ} \mathrm{C}$ for $5 \mathrm{sec}$, and elongation at $72^{\circ} \mathrm{C}$ for $15 \mathrm{sec}$. To confirm the presence of the $B c l$ i polymorphism, $17 \mu \mathrm{L}$ of the PCR product was digested with $2 \mu \mathrm{L}$ of $10 \mathrm{x}$ Restriction Endonuclease Buffer and $15 \mathrm{U}$ of the restriction enzyme $\mathrm{BclI}$ (New England Biolabs, UK) for $1.5 \mathrm{hr}$ at $50^{\circ} \mathrm{C}$. The resulting digested fragments were separated on a $2 \%$ agarose gel to determine the genotypes. For the N363S polymorphism, specific PCR primers were used: $5^{\prime}$-AGTACCTCTGGAGGACA G AT- $3^{\prime}$ and $5^{\prime}$-GTCCATTCTTAAGAAACAGG- $3^{\prime}$ under the same PCR conditions. The restriction enzyme Tsp509I $(10 \mathrm{U})$ was used to digest the PCR products at $65^{\circ} \mathrm{C}$ for 4 hours. For the ER22/EK23 polymorphism, we have used the following primers: $5^{\prime}$-GATTCGGAGTTAACTAAAAG$3^{\prime}$ and $5^{\prime}$-CTACCCTTTACTGGACCCTA- ${ }^{\prime}$, followed by restriction digest using MnI I (New England Biolabs, UK) at $37^{\circ} \mathrm{C}$ for 4 hours. Finally, the Tth111I polymorphism was assessed using the PCR primers: $5^{\prime}$-GGCCACAACAATAACCCAGT- $3^{\prime}$ and $5^{\prime}$-CCTATGACACGTATTTTGTGAAAGT- $3^{\prime}$. The restriction endonuclease Tthl11I (New England Biolabs, UK) was used to digest the PCR products at $65^{\circ} \mathrm{C}$ for 4 hours.

2.10. Statistical Analysis. Q-PCR data are reported as the mean \pm SEM. Statistical analysis was performed by Student's $t$-test and by ANOVA. $P<0.05$ was regarded as statistically significant. We also tested the relationships between continuous predictors (women's age, stress) and infant weight, using Pearson correlations and partial correlations (when adjusting for age and BMI) and using $t$-tests for dichotomous predictors (e.g., planned pregnancy) and ANOVA for testing the relationship between attitude type and infant birth weight, while controlling statistically for relevant confounders such as mothers' age, BMI, pregnancy planning, and pregnancy nutritional habits. 


\section{Results}

3.1. Expression of Placental GAS5 and GRs. Quantitative RT-PCR revealed that GAS5 and all GRs were expressed in human placentas $(n=23)$; 13 were preterm labor ( $<37$ gestational weeks) and 10 were term ( $>37$ gestational weeks) labor, with GAS5 and GR $\alpha$ being the predominant transcripts. In term labor, GR $\alpha$ 's $\Delta \mathrm{Ct}$ was 0.244 compared with 0.006 for GR $\beta, 0.006$ for GR $\gamma, 0.023$ for GR-P, and 0.26 for GAS5. At preterm, the values were 0.278, 0.004 , $0.003,0.006$, and 0.180 for GR $\alpha, \mathrm{GR} \beta, \mathrm{GR} \gamma, \mathrm{GR}-\mathrm{P}$, and GAS5, respectively (see Figure 1(a)). It is evident that the major transcripts in the human placenta are GR $\alpha$ and GAS5. When relative mRNA abundance was calculated, an approximate 4fold change in the GR $\alpha / G R-P$ in the preterm labor group was noted compared with the term group. In addition, a twofold increase in the GR $\alpha$ /GAS5 ratio was also noted in the preterm group compared to the term group (see Table 2).

In term placentas, there was a significant correlation between GR $\beta$ and GR $\gamma(r=0.580, P=0.038)$ and with GR-P $(r=0.980, P<0.001)$. In the preterm group, the dynamics of GR splicing were altered, since GR $\alpha$ correlated with GR-P $(r=0.710, P=0.021)$ and GR $\beta$ correlated with GAS5 $(r=$ $0.792, P=0.011)$. However, no significant correlation was noted in the preterm group between fetal weight or maternal stress and the relative expression of GRs and GAS5. In the term group, the only significant correlation was between GAS5 and maternal stress $(r=-0.711, P=0.021)$.

Due to ethical restrictions, we were only able to assess the expression of GR $\alpha / \beta$ in 4 term and 3 preterm placentas. Since GR is present as different isoforms, multiple bands were observed and there was an expected interpatient variation in the protein expression. Scanning densitometry of the bands corresponding to GR $\alpha / \beta$ normalized over GAPDH revealed no apparent differences in the expression of these variants between the term and the preterm groups (Figure 1(b)).

3.2. Cellular Distribution of GR $\alpha$ and GAS5 in Human Placentas. Immunofluorescence analysis of the GR $\alpha$ protein was performed in human placenta tissue sections. Strong homogeneous staining mainly in the cytoplasm is detected in the syncytiotrophoblast cells on the outermost layer of the placental villi, with some scattered expression in cytotrophoblast cells (Figure 2(a)). Using RNA FISH, GAS5 localized primarily in syncytiotrophoblasts (Figure 2(c)). This is a first time that GAS5 localization has been studied in human placentas.

3.3. Effects of Cortisol on GRs and GAS5 In Vitro. BeWo and JEG-3 cells were treated overnight with cortisol, to mimic moderate and high stress environments in vitro. Before doing so, the expression of GAS5 and GRs was examined in BeWo and JEG-3 cells without administering cortisol. GAS5 was significantly lower in expression in JEG-3 cells when compared to BeWo under basal conditions (Figure 3(a)). For the GRs, significantly higher expression levels were detected only for GR $\gamma$ and GR-P in the JEG-3 cells compared to the BeWo cells (Figure 3(b)).
TABLE 2: Relative mRNA abundance of GR $\alpha$ over GR $\beta$, GR $\gamma$, GR-P, and GAS5.

\begin{tabular}{|c|c|c|}
\hline Ratio & $\operatorname{Term}(n=13)$ & Preterm $(n=10)$ \\
\hline $\mathrm{GR} \alpha / \mathrm{GR} \alpha$ & 1 & 1 \\
\hline $\mathrm{GR} \alpha / \mathrm{GR} \beta$ & 47 & 65 \\
\hline $\mathrm{GR} \alpha / \mathrm{GR} \gamma$ & 38 & 97 \\
\hline GR $\alpha /$ GR-P & 11 & 43 \\
\hline GR $\alpha /$ GAS5 & 0.8 & 1.5 \\
\hline
\end{tabular}

When BeWo and JEG-3 cells were treated with cortisol $10 \mathrm{nM}, 100 \mathrm{nM}$, or $1000 \mathrm{nM}$, the expression of GAS5 was significantly upregulated (all $P<0.05$ ) compared with their corresponding basal levels (Figure 4(a)). The maximal stimulation for GAS5 was at $10 \mathrm{nM}$ of cortisol in JEG-3 cells and at $1000 \mathrm{nM}$ in BeWo. None of the cell lines exhibited dose dependency. However, cortisol treatments did not exert any significant changes in the gene expression of GR $\alpha$ (Figure 4(b)), GR $\beta$ (Figure 4(c)), GR $\gamma$ (Figure 4(d)), and GR-P in either of the cell lines (Figure 4(e)). In addition, there were no apparent changes in protein expression of $\mathrm{GR} \alpha / \beta$ in BeWo cells treated with $10-1000 \mathrm{nM}$ of cortisol, corroborating the qPCR studies (data not shown).

3.4. Maternal and Infant GR Polymorphisms, Maternal Attitudes, and Fetal Birth Weight. Four GR polymorphisms were investigated: BclI, N363S, Tth111I, and ER22/23EK (Table 3). Since the maternal attitude towards the pregnancy was a significant predictor of fetal birth weight, we reexamined this association as a function of the GR genepolymorphisms, resembling a gene-environment interaction and statistically controlling for mothers' age, BMI, pregnancy planning, and pregnancy nutritional habits, to remove any potential sources of statistical bias that could skew our data.

Statistical analysis of the maternal Tht111I polymorphism has shown an inverse correlation between negative maternal attitude and infant birth weight $(r=-0.41, P=0.030)$, only in Tht111 CC polymorphism subgroup. In Tht111 CT, no significant correlations were noted, controlling for age, BMI, pregnancy planning, and consumption of fast food during pregnancy. These data point towards an interaction between stress and genetics, since only in the CC polymorphic GR group did negative maternal attitude predict fetal weight reduction, but not in the CT group, independent of confounders. Hence, the effects of maternal attitudes on fetal weight depend on the mother's polymorphism of GR gene. None of the remaining GR polymorphism subgroups demonstrated any differential correlations between maternal attitudes and fetal weight (data not shown).

\section{Discussion}

The present study extends previous findings and provides evidence for the first time how maternal stress and GR polymorphisms can potentially affect fetal outcome together. As reviewed previously, prenatal maternal stress has been shown to have long-term effects on the psychological as 


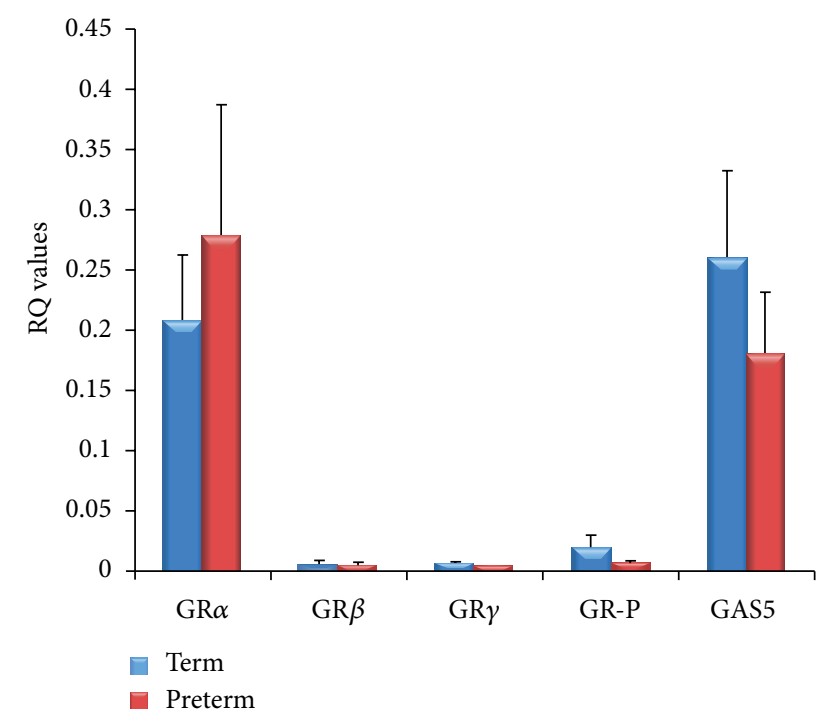

(a)

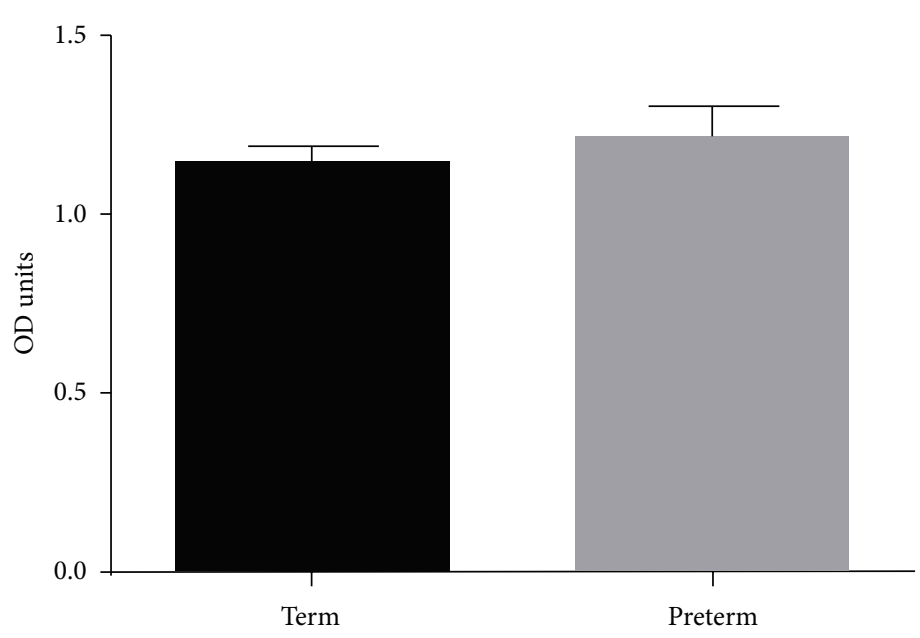

(b)

FIGURE 1: (a) Expression of GR $\alpha, \mathrm{GR} \beta, \mathrm{GR} \gamma, \mathrm{GR}-\mathrm{P}$, and GAS5 in term (blue; $n=13$ ) and preterm (red; $n=10)$ placentas. (b) Protein expression of GRs correcting over GAPDH, in term $(n=4)$ and preterm $(n=3)$ placentas.

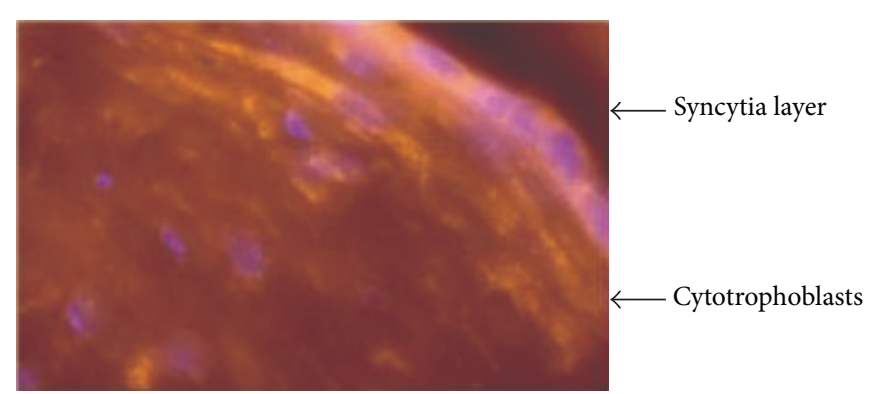

(a)

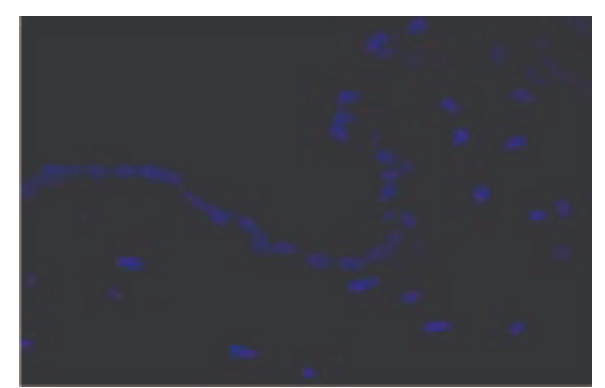

(b)

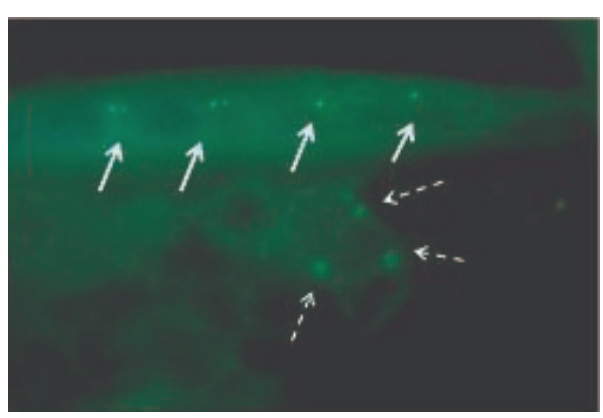

(c)

FIGURE 2: (a) Immunofluorescent analysis demonstrated expression of GR $\alpha$ primarily in the syncytiotrophoblastic layer of term placentas. (b) Negative control, confirmed specificity of immunostaining. (c) RNA FISH confirmed expression of GAS5 in cytotrophoblasts cells (dotted arrows) and syncytiotrophoblasts cells (white arrows).

well as behavioral development of the offspring $[15,16]$. In our cohort, women with negative attitudes exhibited higher levels of stress during pregnancy compared to women with neutral/positive attitudes and gave birth to infants with lower birth weights than those with positive/neutral attitudes towards their pregnancy (500 gr difference [13]).
In terms of the polymorphisms analyses, only the maternal Tth111 polymorphism was suggestive of a geneenvironment interaction since, only in Tth111I (CC), negative versus positive/neutral maternal attitudes towards the pregnancy predicted fetal weight reduction, but not in the Tth111 (GC) group, independent of important confounders. 

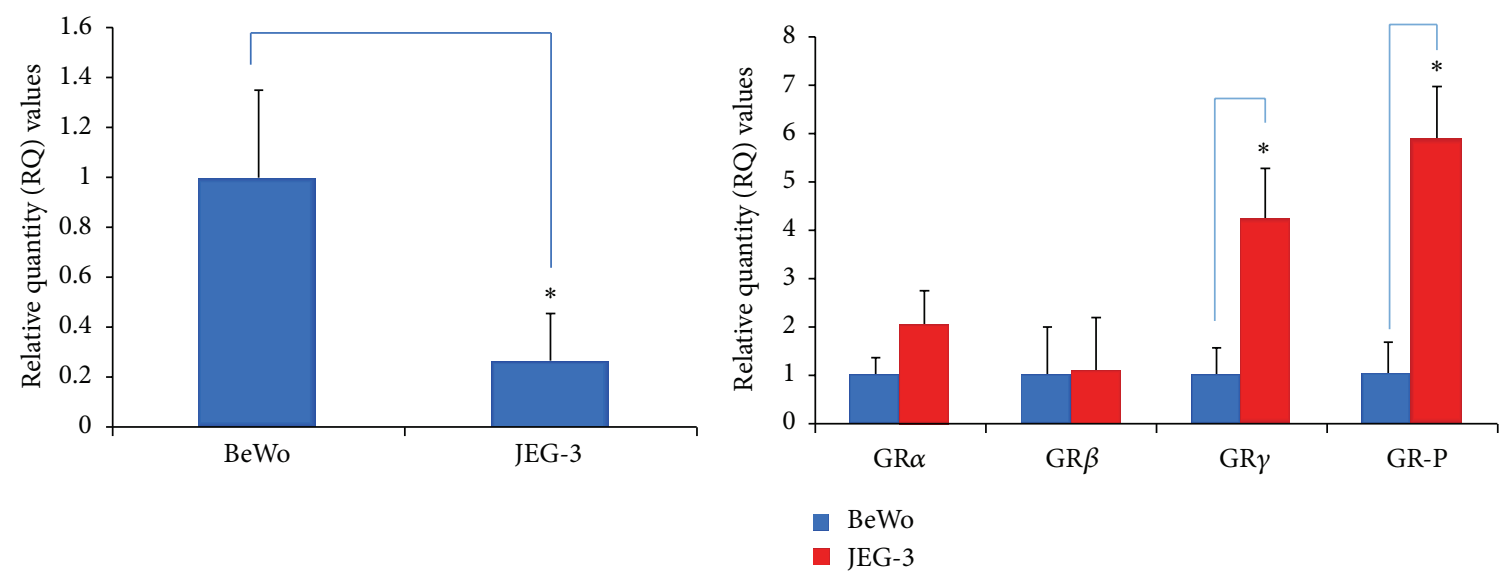

(a)

(b)

Figure 3: (a) Expression of GAS5 in BeWo and JEG-3 cells; ${ }^{*} P<0.05$. (b) Expression of GR $\alpha$, GR $\beta$, GR $\gamma$, and GR-P in BeWo and JEG-3 cells; ${ }^{*} P<0.05$.

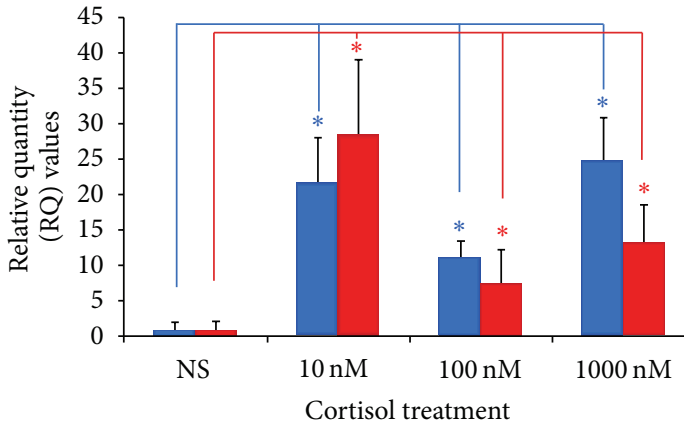

(a)

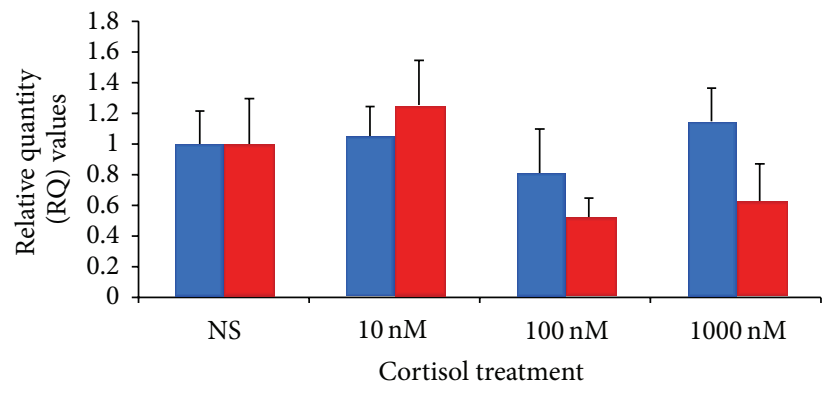

(c)

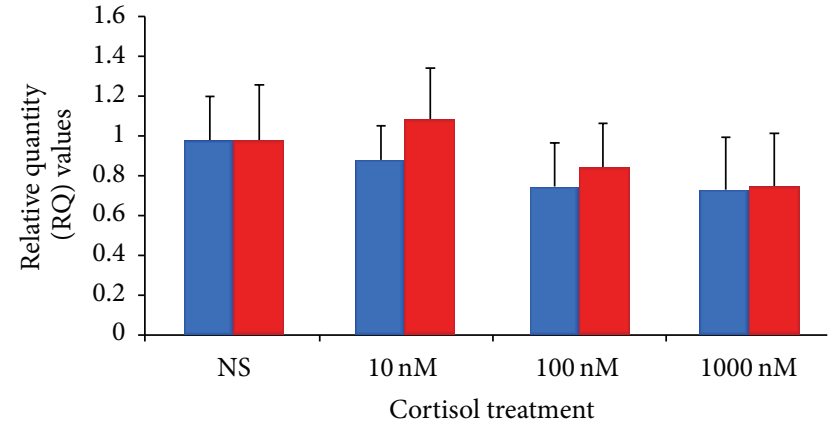

(b)

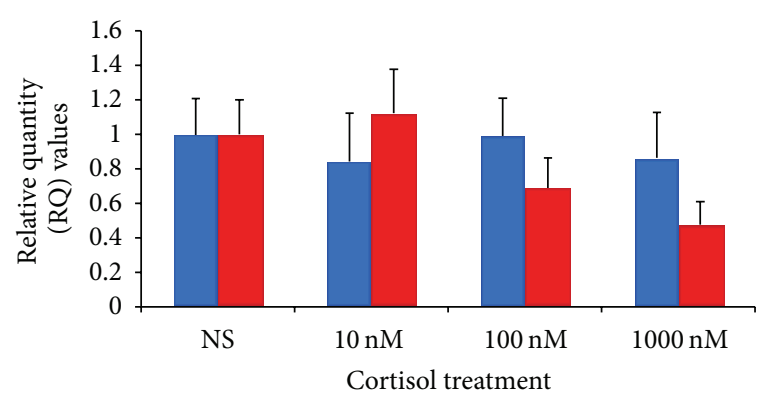

(d)

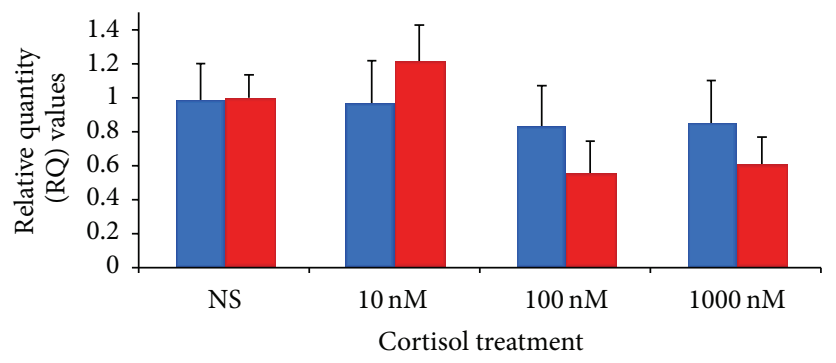

(e)

FIGURE 4: Effects of cortisol on the expression of GAS5 (a), GR $\alpha$ (b), GR $\beta$ (c), GR $\gamma$ (d), and GR-P (e) in JEG-3 (red) and BeWo (blue) placental cell lines. NS: no supplement, ${ }^{*} P<0.05$. 
TABLE 3: Distribution of GR polymorphisms.

\begin{tabular}{|c|c|c|c|}
\hline Polymorphism & Nucleotide change & Genotype & Distribution (\%) \\
\hline \multirow{4}{*}{$B c l \mathrm{I}$} & \multirow{4}{*}{$\mathrm{C} \rightarrow \mathrm{G}$} & & $n=81$ \\
\hline & & GG & $5(6.2)$ \\
\hline & & $\mathrm{CC}$ & $19(23.5)$ \\
\hline & & GC & $57(70.4)$ \\
\hline \multirow{3}{*}{ N363S } & \multirow{3}{*}{ Asp $\rightarrow$ Lys } & & $n=81$ \\
\hline & & wt & $79(97.5)$ \\
\hline & & $\mathrm{Hmz}$ & $2(2.5)$ \\
\hline \multirow{4}{*}{ ThtIIII } & \multirow{4}{*}{$\mathrm{C} \rightarrow \mathrm{T}$} & & $n=81$ \\
\hline & & $\mathrm{CC}$ & $35(43.2)$ \\
\hline & & TT & $2(2.5)$ \\
\hline & & CT & $44(54.3)$ \\
\hline \multirow{3}{*}{$E R 22 / 23 E K$} & \multirow{3}{*}{ Arg $\rightarrow$ Lys } & & $n=81$ \\
\hline & & wt & $78(96.3)$ \\
\hline & & $\mathrm{Htz}$ & $3(3.7)$ \\
\hline
\end{tabular}

These confounders included women's age and BMI and were not explained by gestational age. Additionally, multiple other immune symptoms and demographic variables tested were also not predictive of fetal weight. This is the first time that a gene-environment interaction between a GR polymorphism and maternal attitudes towards pregnancy was found, in relation to fetal weight. To this date there has been some contradicting evidence as to the role of these polymorphisms in fetal outcomes [17-19].

The human placenta is exposed to increased levels of cortisol as pregnancy progresses [20] and its effects are mediated via binding and activating the GR. However, controversy surrounds the exact mechanisms by which these responses are regulated. GR alternative splicing might also influence the subsequent activation of signalling pathways by glucocorticoids [20]. In our study, we have shown that all known transcripts of GR splice variants are expressed in the human placenta with GR $\alpha$ being the predominant transcript in all categories studied. These data corroborate a previous preliminary study of placental GRs [20]. Moreover, we demonstrate for the first time the expression of GAS5 in human placentas. We decided to incorporate GAS5 in the current study as it can act as a GR DNA binding decoy and as a result compromise its activity [8]. Interestingly, GAS5 and GR $\alpha$ were the predominant transcripts in both term and preterm placentas.

Here, we provide further information about the regulation of this transcript by cortisol using two in vitro models as it is upregulated by cortisol in a dose-independent manner. This finding provides further evidence of regulation of GAS5 by stress and corroborates initial in vivo data in mice [21]. In this study using C57BL/6 male mice, stress induced GAS5 RNA levels in the hippocampus and this increase was accompanied by a rise of corticosterone levels [22]. These in vitro and in vivo observations together are highly suggestive of a functional link between stress and this ncRNA. Moreover, when we performed RNA FISH, the GAS5 transcript was localized almost exclusively in the syncytiotrophoblast layer of the human placenta and colocalizes GR $\alpha$. In view of previous data in HeLa cells, where GAS5 translocates from the cytoplasm into the nucleus with GR in response to dexamethasone [8], this colocalization is highly suggestive of a potential crosstalk at placental level between GAS5 and the GR.

Preterm labor is associated with high mortality and morbidity [22] and a recent study pointed towards an association between maternal stress and complications of pregnancy, especially preterm birth [23]. GR $\beta$ differs from $\mathrm{GR} \alpha$ on the C-terminus of the receptor protein. There is some controversy surrounding the exact function of GR $\beta$, but it appears to exert a dominant-negative effect on GR $\alpha$ induced transcriptional activity [8]. Moreover, it fails to bind glucocorticoids and activate subsequent transcriptional events [24]. GR $\gamma$ is a ligand-dependent transcription factor with reduced transactivating activity and its function is still under investigation. In our clinical samples, GR $\gamma$ is present at much lower levels than the GR $\alpha$ isoform in the placentas studied. Similarly, little is known about the role of GR-P, a truncated isoform that lacks a large part of the ligand-binding domain, including the domains for silencing of GR in the absence of hormone and transcriptional activation [24].

In our study, an approximate 4-fold change in the GR $\alpha /$ GR-P in preterm labor was detected. Johnson et al. have shown that placental GR-P mRNA levels were reduced significantly after spontaneous labor [20]. A twofold increase in the GR $\alpha$ /GAS5 ratio was also noted in the preterm group compared with the term group of women. It is attractive therefore to hypothesise that the change in the ratio of the splicing isoforms alters the responsiveness of placental GRs to cortisol and that this may affect gestational age. We would like to propose a potential model where, during preterm birth, $\mathrm{GR} \alpha$ is the predominant receptor since there is a decrease in negative regulators such as GR $\beta$, GR $\gamma$, and the "pseudoGRE" GAS5. These ratio changes will ultimately lead to an augmented response towards glucocorticoids with potential detrimental effects for the mother and the fetus. It is possible 
that this change of relative transcript abundance ratio might be involved in the correlation between negative maternal attitudes (hence highly stressed) and fetal birth weight.

In terms of the polymorphic study, our study provides a novel insight into the involvement of GR polymorphisms in pregnancy outcome. We have identified a specific group of mothers (Tht $I I I$ I polymorphism, CC group) in whom maternal attitudes predicted fetal weight. In a past study, a similar gene-environment interaction was noted between the ER22/23EK polymorphism and the effect of childhood adversity on depression [17].

We acknowledge that measurement of GR polymorphisms posed certain limitations, for example, the use of cell lines as in vitro experimental models. Although both cell lines (JEG-3 and BeWo) could represent a cytotrophoblastic milieu in vitro, they have differences in their fusogenic capacities. In addition, microarray analyses demonstrated that many transcripts were differentially expressed between JEG-3 and BeWo cells [25]. It would be of interest to repeat these experiments in primary cell lines of syncytialised trophoblasts. This experiment would provide a better insight into the regulation of GAS5 by cortisol. However and despite these limitations, there is a wealth of literature using those two cell lines as experimental models to study placental function. It would also be of interest to expand these observations in human myometrium that is a key organ responsible for quiescence and contractility responses and also assess whether changes in GR transcripts are due to labor or nonlabor. To test this, we have performed qPCR for all GRs and GAS5 in the same cohort of placentas divided this time to labor $(n=18)$ and nonlabor $(n=5)$. There was no apparent change in the expression of any of the genes in these two categories (data not shown). Therefore, at placental level, the contractile status does not really affect GR transcription.

We acknowledge that our sample included small numbers in certain categories of polymorphic groups. Moreover, the nature of maternal stress was not identified and further analytical approaches are needed to provide conclusive evidence for a gene-environment interaction. Nevertheless, the statistically significant effect and the size of differences observed between mothers with negative versus positive and neutral attitudes in the Tht111I CC polymorphism group suggest that this effect may be robust. Second, the distribution of $B c l$ I polymorphism seen in this sample may be unique, since there are important geographical/ethnic differences in the prevalence of these polymorphisms. It should be emphasized that, in the present study, we included a fairly homogeneous cohort of Mediterranean patients from Crete. Despite these limitations, this is the first study to demonstrate a genematernal environment synergism in relation to infant birth weight, using a very brief assessment of maternal attitudes to pregnancy. Should these data be replicated in a much wider cohort, given the simplicity in assessing such attitudes and the feasibility to identify the homozygous group of women early on in pregnancy, these findings may have significant implications for public health and prevention. For example, based on the polymorphic profile and our brief assessment of mothers' attitude towards the pregnancy, we could screen noninvasively and identify mothers during pregnancy that may benefit from stress-management strategies, and this could possibly dramatically improve health outcomes for the mother as well as the fetus.

\section{Conflict of Interests}

The authors declare that there is no conflict of interests regarding the publication of this paper.

\section{References}

[1] M. Lobel, D. L. Cannella, J. E. Graham, C. DeVincent, J. Schneider, and B. A. Meyer, "Pregnancy-specific stress, prenatal health behaviors, and birth outcomes," Health Psychology, vol. 27, no. 5, pp. 604-615, 2008.

[2] W. J. E. Tissing, J. P. P. Meijerink, M. L. den Boer, and R. Pieters, "Molecular determinants of glucocorticoid sensitivity and resistance in acute lymphoblastic leukemia," Leukemia, vol. 17, no. 1, pp. 17-25, 2003.

[3] L. Pujols, J. Mullol, J. Roca-Ferrer et al., "Expression of glucocorticoid receptor $\alpha$ - and $\beta$-isoforms in human cells and tissues," American Journal of Physiology: Cell Physiology, vol. 283, no. 4, pp. C1324-C1331, 2002.

[4] M. Honda, F. Orii, T. Ayabe et al., "Expression of glucocorticoid receptor $\beta$ in lymphocytes of patients with glucocorticoidresistant ulcerative colitis," Gastroenterology, vol. 118, no. 5, pp. 859-866, 2000.

[5] R. H. Oakley, J. C. Webster, C. M. Jewell, M. Sar, and J. A. Cidlowski, "Immunocytochemical analysis of the glucocorticoid receptor alpha isoform (GR $\alpha)$ using a GR $\alpha$-specific antibody," Steroids, vol. 64, no. 10, pp. 742-751, 1999.

[6] M. de Castro, S. Elliot, T. Kino et al., "The non-ligand binding $\beta$-isoform of the human glucocorticoid receptor (hGR $\beta$ ): tissue levels, mechanism of action, and potential physiologic role," Molecular Medicine, vol. 2, no. 5, pp. 597-607, 1996.

[7] C. Schneider, R. M. King, L. Philipson et al., "Genes specifically expressed at growth arrest of mammalian cells," Cell, vol. 54, no. 6, pp. 787-793, 1988.

[8] T. Kino, D. E. Hurt, T. Ichijo, N. Nader, and G. P. Chrousos, "Noncoding RNA Gas5 is a growth arrest- and starvationassociated repressor of the glucocorticoid receptor," Science Signaling, vol. 3, no. 107, p. ra8, 2010.

[9] T. F. Oberlander, J. Weinberg, M. Papsdorf, R. Grunau, S. Misri, and A. M. Devlin, "Prenatal exposure to maternal depression, neonatal methylation of human glucocorticoid receptor gene (NR3C1) and infant cortisol stress responses," Epigenetics, vol. 3, no. 2, pp. 97-106, 2008.

[10] E. F. C. van Rossum and S. W. J. Lamberts, "Polymorphisms in the glucocorticoid receptor gene and their associations with metabolic parameters and body composition," Recent Progress in Hormone Research, vol. 59, no. 1, pp. 333-357, 2004.

[11] L. Manenschijn, E. L. T. van den Akker, S. W. J. Lamberts, and E. F. C. van Rossum, "Clinical features associated with glucocorticoid receptor polymorphisms," Annals of the New York Academy of Sciences, vol. 1179, pp. 179-198, 2009.

[12] D. Mparmpakas, E. Zachariades, A. Goumenou, Y. Gidron, and E. Karteris, "Placental DEPTOR as a stress sensor during pregnancy," Clinical Science, vol. 122, no. 7, pp. 349-359, 2012.

[13] D. Mparmpakas, A. Goumenou, E. Zachariades et al., "Immune system function, stress, exercise and nutrition profile can affect pregnancy outcome: lessons from a Mediterranean cohort," 
Experimental and Therapeutic Medicine, vol. 5, no. 2, pp. 411418, 2013.

[14] Y. Koga, A. Matsuzaki, A. Suminoe, H. Hattori, S. Kanemitsu, and T. Hara, "Differential mRNA expression of glucocorticoid receptor $\alpha$ and $\beta$ is associated with glucocorticoid sensitivity of acute lymphoblastic leukemia in children," Pediatric Blood and Cancer, vol. 45, no. 2, pp. 121-127, 2005.

[15] E. J. H. Mulder, P. G. Robles de Medina, A. C. Huizink, B. R. H. van den Bergh, J. K. Buitelaar, and G. H. A. Visser, "Prenatal maternal stress: effects on pregnancy and the (unborn) child," Early Human Development, vol. 70, no. 1-2, pp. 3-14, 2002.

[16] R. M. Reynolds, J. Labad, C. Buss, P. Ghaemmaghami, and K. Räikkönen, "Transmitting biological effects of stress in utero: implications for mother and offspring," Psychoneuroendocrinology, vol. 38, no. 9, pp. 1843-1849, 2013.

[17] P. M. Bet, B. W. J. H. Penninx, Z. Bochdanovits et al., "Glucocorticoid receptor gene polymorphisms and childhood adversity are associated with depression: new evidence for a gene-environment interaction," American Journal of Medical Genetics B: Neuropsychiatric Genetics, vol. 150, no. 5, pp. 660669, 2009.

[18] M. J. J. Geelhoed, E. A. P. Steegers, J. W. Koper et al., “Glucocorticoid receptor gene polymorphisms do not affect growth in fetal and early postnatal life. The Generation R Study," BMC Medical Genetics, vol. 11, no. 1, article 39, 2010.

[19] R. Bertalan, A. Patocs, B. Vasarhelyi et al., "Association between birth weight in preterm neonates and the BclI polymorphism of the glucocorticoid receptor gene," Journal of Steroid Biochemistry and Molecular Biology, vol. 111, no. 1-2, pp. 91-94, 2008.

[20] R. F. Johnson, N. Rennie, V. Murphy, T. Zakar, V. Clifton, and R. Smith, "Expression of glucocorticoid receptor messenger ribonucleic acid transcripts in the human placenta at term," Journal of Clinical Endocrinology and Metabolism, vol. 93, no. 12, pp. 4887-4893, 2008.

[21] I. Meier, L. Fellini, M. Jakovcevski, M. Schachner, and F. Morellini, "Expression of the snoRNA host gene gas5 in the hippocampus is upregulated by age and psychogenic stress and correlates with reduced novelty-induced behavior in C57BL/6 mice," Hippocampus, vol. 20, no. 9, pp. 1027-1036, 2010.

[22] S. Beck, D. Wojdyla, L. Say et al., "The worldwide incidence of preterm birth: a systematic review of maternal mortality and morbidity," Bulletin of the World Health Organization, vol. 88, no. 1, pp. 31-38, 2010.

[23] N. Roy-Matton, J.-M. Moutquin, C. Brown, N. Carrier, and L. Bell, "The impact of perceived maternal stress and other psychosocial risk factors on pregnancy complications," Journal of Obstetrics and Gynaecology Canada, vol. 33, no. 4, pp. 344352, 2011.

[24] B. Sánchez-Vega, N. Krett, S. T. Rosen, and V. Gandhi, "Glucocorticoid receptor transcriptional isoforms and resistance in multiple myeloma cells," Molecular Cancer Therapeutics, vol. 5, no. 12, pp. 3062-3070, 2006.

[25] D. W. Burleigh, C. M. Kendziorski, Y. J. Choi et al., "Microarray analysis of BeWo and JEG3 trophoblast cell lines: identification of differentially expressed transcripts," Placenta, vol. 28, no. 5-6, pp. 383-389, 2007. 


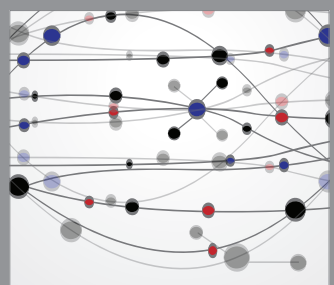

The Scientific World Journal
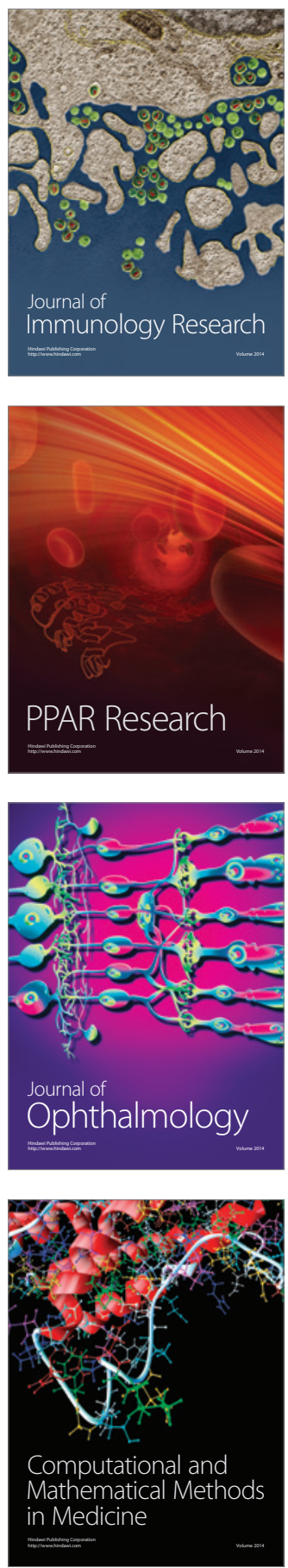

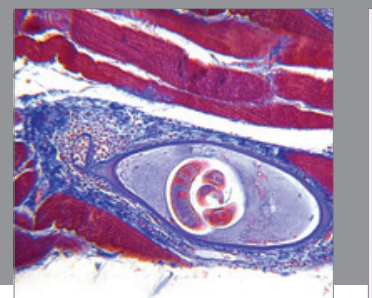

Gastroenterology

Research and Practice
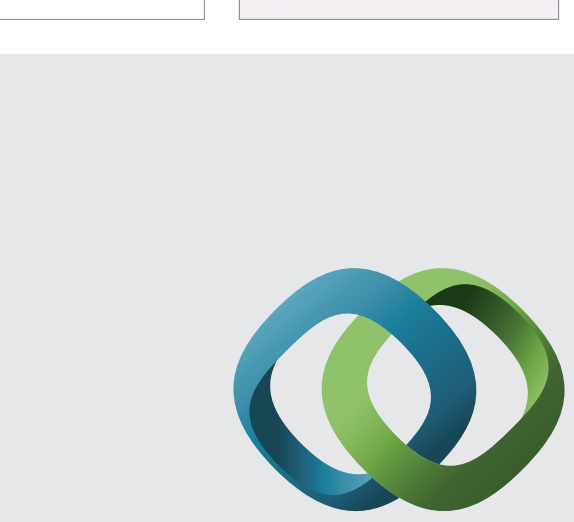

\section{Hindawi}

Submit your manuscripts at

http://www.hindawi.com
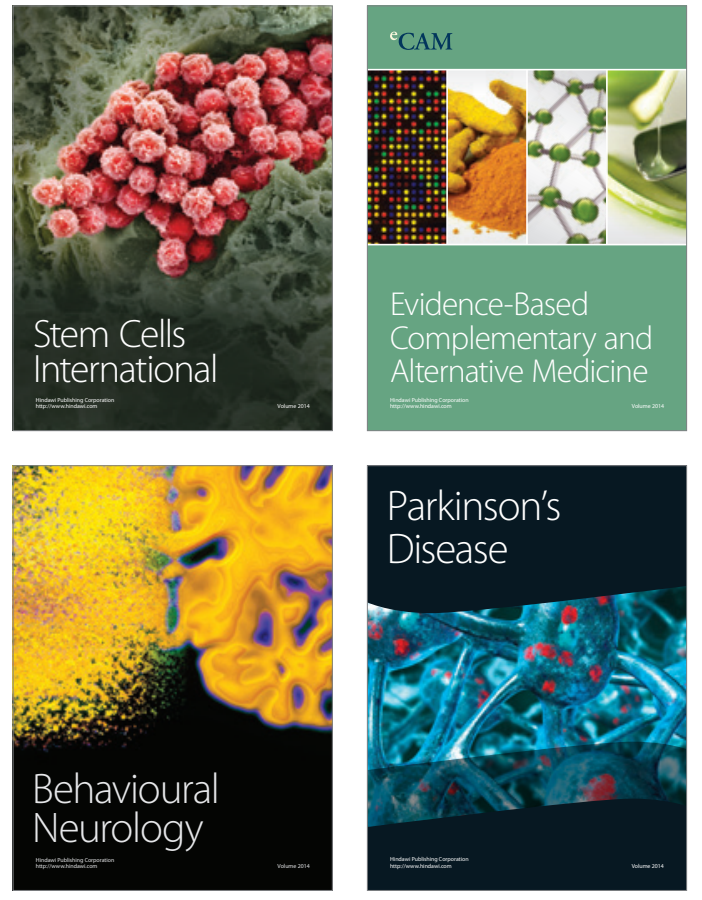
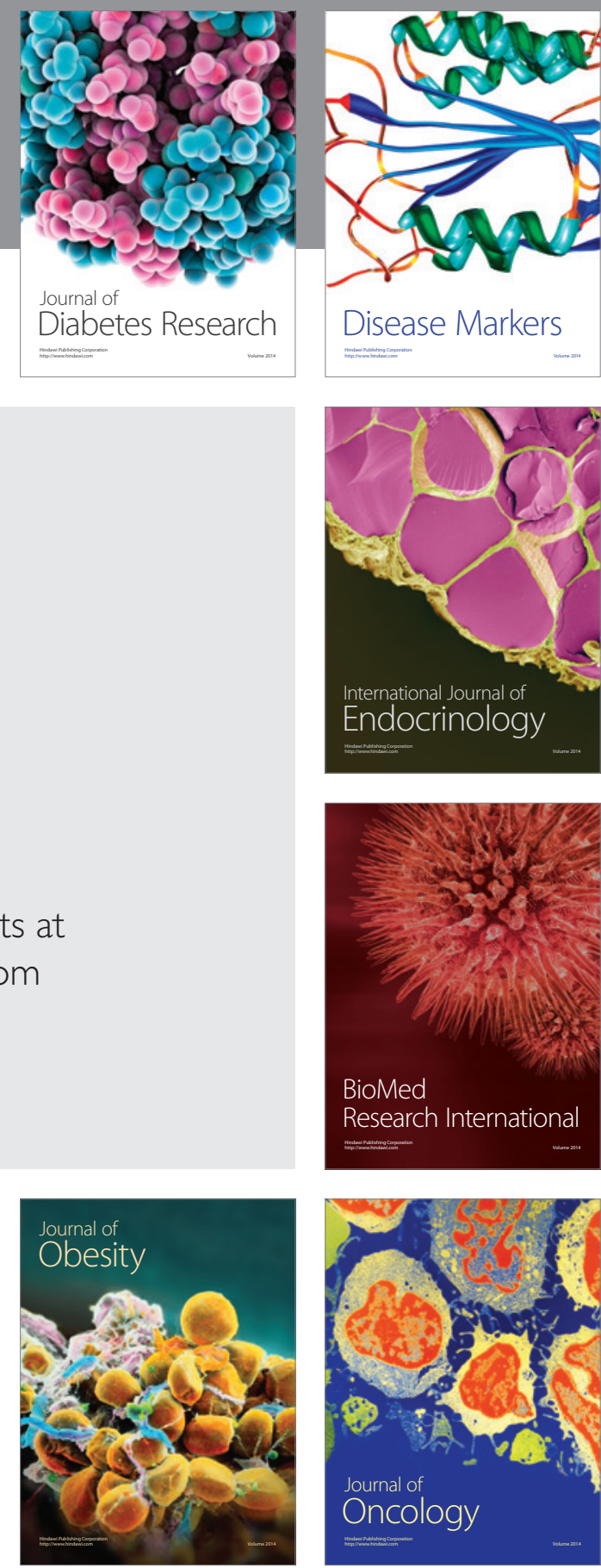

Disease Markers
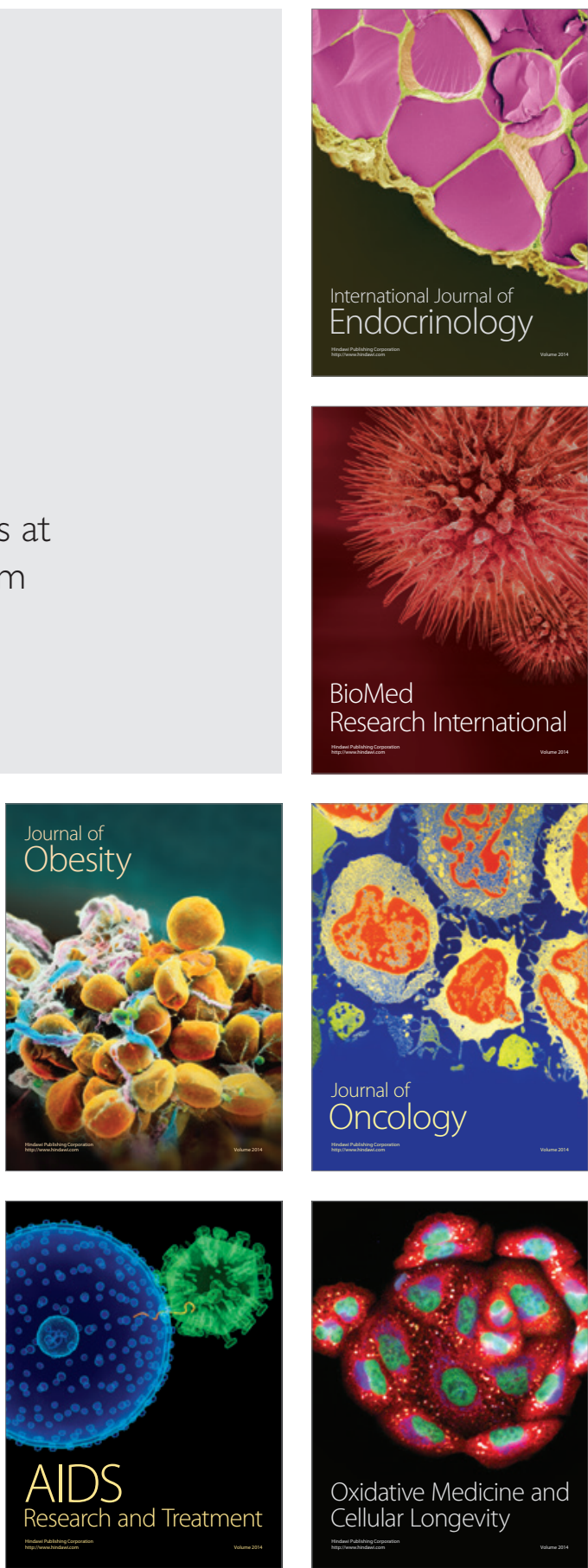